Article

\title{
Scanner-Based Minirhizotrons Help to Highlight Relations between Deep Roots and Yield in Various Wheat Cultivars under Combined Water and Nitrogen Deficit Conditions
}

\author{
François Postic ${ }^{1,2}$, Katia Beauchêne ${ }^{2}$, David Gouache ${ }^{3}$ and Claude Doussan ${ }^{1, *(D)}$ \\ 1 INRA-UMR 1114 EMMAH INRA/UAPV, 84914 Avignon, France; f.postic@yahoo.fr \\ ARVALIS-Institut du végétal, 41240 Beauce la romaine, France; K.BEAUCHENE@arvalis.fr \\ 3 Terres Inovia, 78850 Thiverval-Grignon, France; d.gouache@terresinovia.fr \\ * Correspondence: claude.doussan@inra.fr; Tel.: +33-432-72-2238
}

Received: 17 April 2019; Accepted: 4 June 2019; Published: 7 June 2019

check for updates

\begin{abstract}
Breeding for crops in the context of climate change necessitates phenotyping tools for roots in field conditions. Such in-field phenotyping requires the development of rapid and non-destructive measurement techniques for the screening of relevant root traits under sub-optimal conditions. In this study, we used scanner-based minirhizotrons to measure in situ the root length and surface/volume densities of roots for four wheat varieties, under four different growth conditions: irrigated and rainfed coupled with optimal and sub-optimal $\mathrm{N}$ fertilization under a Mediterranean climate. For all the treatments, grain yield correlates with minirhizotron-based root surface density measured at anthesis $\left(r^{2}=0.48\right)$. Irrigated and rainfed conditions led to contrasted relations between roots and grain yield: no correlation was found in irrigated plots, while under rainfed conditions and sub-optimal fertilization, the higher yields are related to a higher root colonization of the deeper soil layers $\left(r^{2}=0.40\right)$. Shoot biomass was correlated to grain yield in irrigated conditions, but not in rainfed conditions. However, for the latter, the total root weight, the proportion of which being mainly located in the top soil, is not related to the grain yield. In this way, we show the relationship between these higher grain yields and a stress avoidance mechanism of the root system characterized by a higher root density in the deep soil layers. Thus, unlike shoot biomass measurements, scanner-based minirhizotron allows the direct detection of such a stress-related root development, and therefore opens the door to a better prediction of grain yield.
\end{abstract}

Keywords: wheat; root plasticity; minirhizotron; drought resistance; nitrogen stress

\section{Introduction}

Driven by a growing world population, cereal demand and production is predicted to increase by $30 \%$ to $50 \%$ in 2050 relative to 2005 [1,2]. Most of this increase is expected to come from an increase in yield and mostly from genetic improvement [1,3]. However, climate change associated with an increase in uncertainty and variability in precipitations and an increase in temperature, challenges yield improvement. It is already the case in top producers of Western Europe such as France where climate change is identified as a factor to wheat yield stagnation since 1995-1998 [4]. Among climatic factors, spring droughts and high temperatures are the main limiting factors for winter cereal crop productions. Temperate regions, such as Northern France, could face a dramatic yield decrease caused by droughts similar to those currently occurring in southern regions, which are characterized by highly variable precipitation during spring and high temperatures during late spring [5]. Concomitantly to 
climate change, intensive agricultural production also faces sustainability issues related to increasing pressures on water resources and availability of fertilizers as well as environmental negative impacts.

More stressful conditions may impact large areas in the future and there is a need to determine crop plant traits that would improve or maintain the yield. Historically, the improvement of crops and agricultural techniques targeted on increasing shoot biomass and grain yield, while overlooking the root system in crop production. Breeding also resulted in an indirect selection of root traits. For example, in the case of wheat, the introduction of dwarfism genes in modern wheat varieties has been related to a reduction in the root biomass and root length [6]. However, the root system ensures crucial functions, such as water and nutrient uptakes, and its role is determinant under limiting low inputs conditions $[7,8]$. The root traits associated with the efficient use of available water and fertilizers by crops, for variable deficit conditions, would be an important feature in the selection of the future phenotypes.

Crops differ in root system architecture and water capture ability and, in relation with drought resistance, root traits can be identified at the vegetative or reproductive stages and defined either from local or global characteristics of the root system architecture (RSA). At the root system scale, Monti et al. [9] showed that energy crops showing a more top-rooted pattern could be more efficient in retrieving water in a wet environment than deeper rooted crops, but at the expense of greater sensitivity to water shortage. In contrast, specific traits of the root system, often measured on seedlings, can be also related to drought resistance. For example, the root angle modulates the tolerance to drought in generating a variable pattern of horizontal relative to vertical exploration of soil by roots [10].

With the aim of identifying the heritability and genetic determinants of root traits, mainly at relatively young stages, different types of root observation facilities have been developed in relation with high-throughput phenotyping requirements for modern breeding programs. Pot based experiments at the laboratory scale allow a high control of environmental conditions and repeatability with detailed investigations of the root systems thanks to imaging techniques such as rhizoponics [11], X-ray tomography [12], magnetic resonance imaging [13] or the growth and luminescence observatory [14]. However, a major disadvantage of these techniques is that the container size has an effect on growth and the root phenes. At a greater spatial scale, but at the cost of the development of large subterranean facilities, rhizolysimeters allow experiments with larger containers size that can be heavily equipped to monitor soil parameters and root development estimated with minirhizotron [15].

However, in situ root development and functioning result from the expression of a myriad of genes triggered by interactions between the plant genome and the environment. Resulting from this genotype-environment interaction $(\mathrm{G} \times \mathrm{E})$, the screening of wheat root traits under controlled environment has been shown not always representative for field conditions [16], which makes the genetic or molecular identification of beneficial root traits challenging for plant breeders. Field and soil environments are biologically, physically and chemically heterogeneous resulting in alteration of root growth response trough plasticity of the root system. That is the case for the distribution of nutrients in the soil which affects the root distribution, and, for example, the shallow or deep distribution of nitrogen induces shallow- or deep-root systems [17].

Moreover, the interaction of multiple abiotic stresses in relation with roots functioning and development is rarely examined, particularly in the field, and most of the literature focuses on interaction involving temperature [18]. For wheat, studies conducted under field and near-field conditions show that a water deficit induces a deeper rooting [19]. A low nitrogen fertilization can also induce a higher proportion of deep roots, especially when water table at seeding time is low [20], while nitrogen fertilization increased the total root length by $30 \%$ [19]. Nonetheless, the combination of these two stresses—drought and nitrogen deficit—results in an overall lower root density over the soil profile [21,22].

Field-studies combine multiple interactions, with most of the soil environment being beyond control and with a limited access to the quantification of occurring factors. Despite a lower control on growth conditions, such field-based studies are needed for identifying relevant root traits and are 
a necessary step for understanding the root system response to various soil conditions. Their major disadvantages lie in that they are labor and time expensive, mostly destructive, and affected by soil heterogeneity. For root quantification, soil coring, shovelomics [23] and minirhizotrons [24] are the main techniques used. Beyond their actual time-consumption, field sampling methods remain destructive and can lead to oversized experimental installations [25].

Among existing sampling methods, minirhizotron, an invasive but non-destructive technique, allows the dynamic study of root growth. This technique consists in observing roots in situ through a transparent tube inserted into the soil. Most minirhizotron applications used video recorders (BTX-100, Bartz Technology Company, Santa Barbara, CA, USA) capturing images of small surface area $\left(4 \mathrm{~cm}^{2}\right)$, which made the recording of a whole tube time-expensive and exposed to positional errors. As a recent technology, minirhizotrons can now be imaged by a rotary scanner that captures $400 \mathrm{~cm}^{2}$ images (CI-600, CID Bio-Science, Camas, WA, USA), so that the complete surface of a $20 \mathrm{~cm}$-long tube, with a $7 \mathrm{~cm}$ diameter, is obtained within a single scan. This better practicability could lead to an increase in the number of available observational data about plant roots. However, most root image processing softwares are not designed for images featuring a soil background, as found in the images from minirhizotrons. For example, beyond reported biases [26], WhinRhizo-the most widely used software-features an automatic root detection conceived for white background images. Nevertheless, once roots are identified on the images, minirhizotrons allow for the rapid assessment of root diameter and root length, and thus require less labor and time than other field-based techniques, particularly for deep root observation.

In the field of crop research, a rotary scanner minirhizotron was used in a prior study for evaluating the influence of tillage on wheat root system [27]. With this technique, the authors obtained root data that successfully explained the higher rainfed wheat productivity under no-tillage. However, to our knowledge, rotary scanner minirhizotron has not been yet employed to measure root systems of crops under nutrient- or water-stress conditions and the potential of this minirhizotron technique to screen for root characteristics remains unknown.

In this study, we propose to (i) test a methodology to convert root length observed with minirhizotron into root mass found with standard auger sampling, (ii) evaluate the root data with respect to the dynamics of physiological traits, and (iii) to examine the relevance of such minirhizotron measures of roots in multi-stress trial for various wheat cultivars.

\section{Materials and Methods}

\subsection{The Field Site}

Field experiments (Figure 1a) were conducted in Gréoux-les-Bains, south-east France $\left(43^{\circ} 7478^{\prime} \mathrm{N}\right.$, $5^{\circ} 8519^{\prime}$ E), on a heterogeneous Fluviosol with a silt loam texture. Located in the Mediterranean climatic region, the mean annual rainfall over the last 20 years is $650.3 \mathrm{~mm}$ (distributed as $32 \%$ in October-December; $18 \%$ in January-March; $28 \%$ in April-June; and 22\% for July-September); the average annual potential evapotranspiration (PET) is $955.5 \mathrm{~mm}$; and for temperature: mean annual temperature $12.68{ }^{\circ} \mathrm{C}$; average temperature of the coldest month $4.5^{\circ} \mathrm{C}$; average temperature of the warmest month $21.8{ }^{\circ} \mathrm{C}$. The weather and temperature data (Figure 2) were obtained from a meteorological station located $700 \mathrm{~m}$ from the experimental plots. During the growth of winter wheat, the cumulated rainfall was $539.7 \mathrm{~mm}$ while PET was $553.0 \mathrm{~mm}$. 


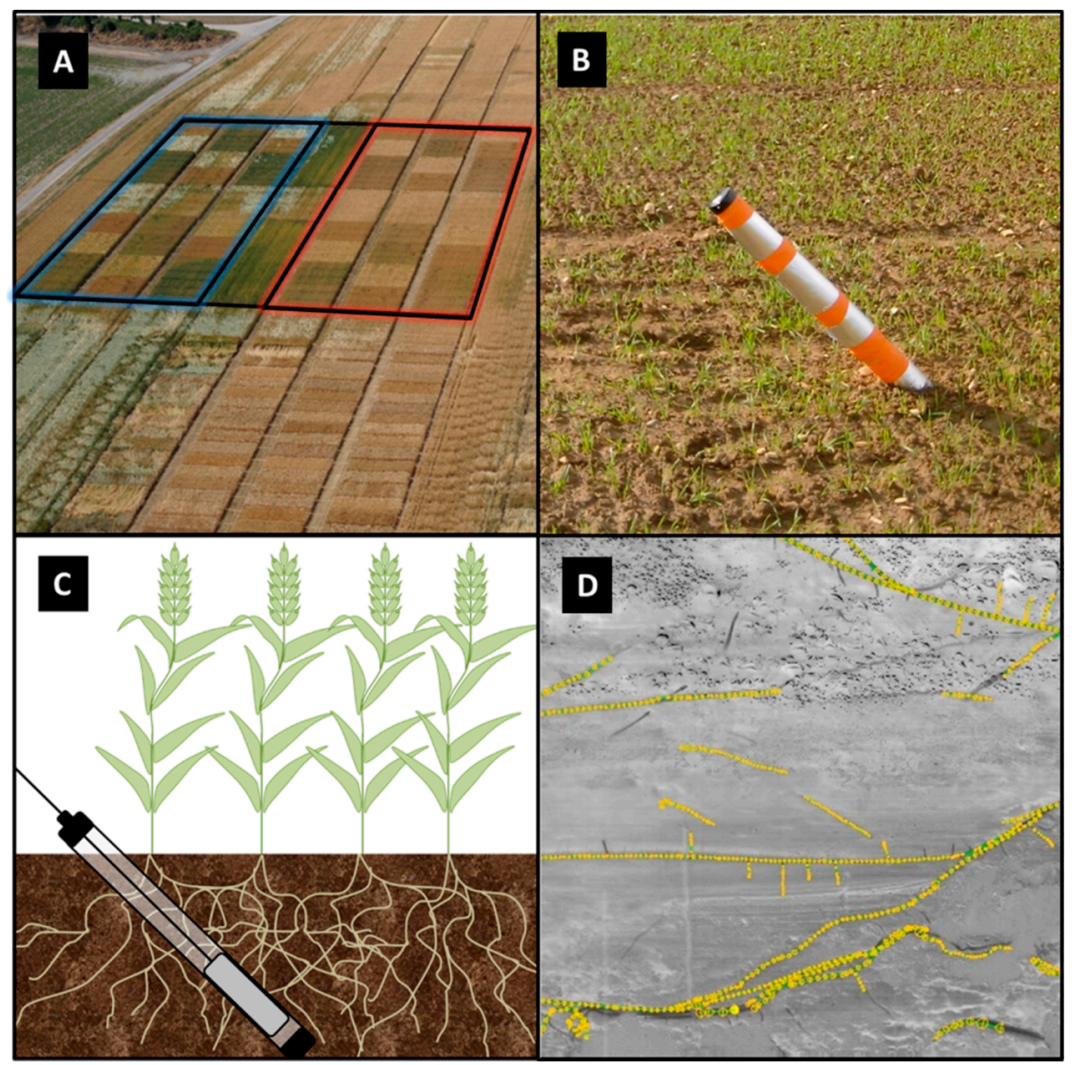

Figure 1. Illustration of in situ root measurements process. (A) Picture of the experimental field after anthesis. Irrigated plots are highlighted in blue, and rainfed plots are highlighted in red. (B) Picture of a minirhizotron installed after emergence. Covering thermal insulation material is maintained on the tube by orange tape. (C) Diagram of the minirhizotron principle. The clear plastic tube is inserted at a $45^{\circ}$ angle, and root impacts on the tube are captured by a rotary scanner. (D) Screenshot of in-progress semi-automatic detection of root on captured images using Smartroot.

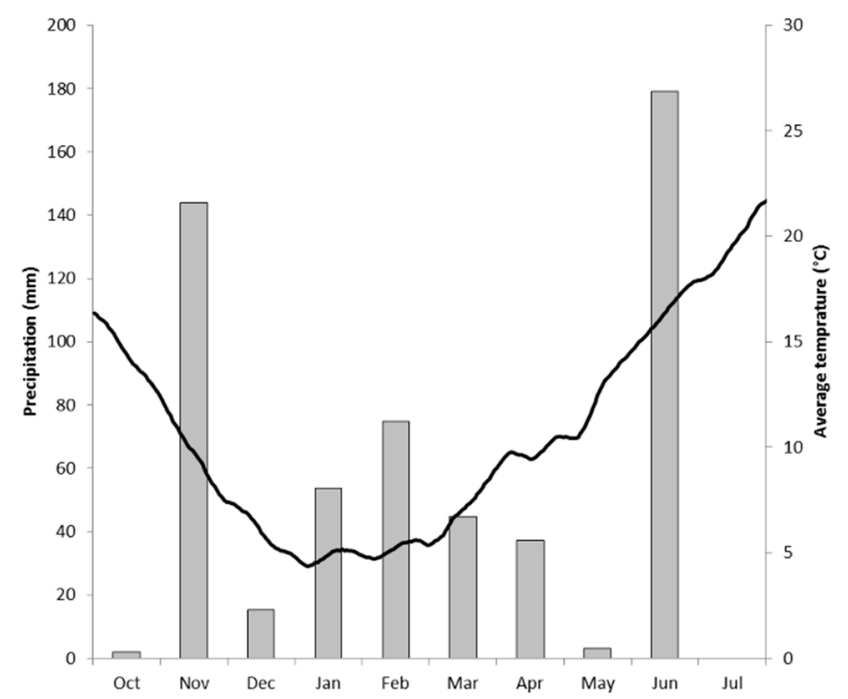

Figure 2. Plot of the weather data for the field site during the experimental period. From mid-October 2014 to mid-July 2015, monthly precipitations (mm) and ten-days' average air temperature $\left({ }^{\circ} \mathrm{C}\right)$ are displayed. Over the experimental period, the cumulated rainfall was $537.9 \mathrm{~mm}$.

On this field, the soil electrical resistivity correlates negatively with soil depth (electrical resistivity map provided in Supplementary Figure S1), thus low values denote deep soil (about 1-1.2 m), while 
high values correspond to shallow soil $(0.4-0.5 \mathrm{~m})$. Electrical resistivity data were produced using the automatic resistivity profiling technique (Geocarta, France). The apparent resistivity was estimated down to $1.7 \mathrm{~m}$ depth and the position of plots was superimposed on this map. Estimations of the soil depth by coring coupled with the resistivity map indicated that the area of resistivity lower than $78 \Omega$ $\mathrm{m}$ were deep soils area. The scale relating resistivity to soil depth is estimated as follows: $29-78 \Omega \mathrm{m}=$ $71-120 \mathrm{~cm}, 78-126 \Omega \mathrm{m}=40-70 \mathrm{~cm}, 126-175 \Omega \mathrm{m}=30-40 \mathrm{~cm}$, and $175-275 \Omega \mathrm{m}<30 \mathrm{~cm}$.

\subsection{Experimental Design}

The study took place during the 2014-2015 season. The winter wheat crops were submitted to contrasted water and $\mathrm{N}$ treatments including: optimal conditions: irrigation and $\mathrm{N}$ non-limiting $(\mathrm{I}+\mathrm{N}+)$, irrigation with $\mathrm{N}$ limitation $(\mathrm{I}+\mathrm{N}-)$, rainfed with $\mathrm{N}$ non-limiting $(\mathrm{I}-\mathrm{N}+)$, rainfed and $\mathrm{N}$ limitation ( $\mathrm{I}-\mathrm{N}-$ ). The precise $\mathrm{N}$ supply is described in the next section. The four wheat varieties were APACHE, HYSTAR, NOGAL (French elite bread wheats, Triticum aestivum L.) and MIRADOUX (French durum wheat, Triticum durum Desf.). The durum wheat was reputed to be more tolerant to limiting conditions, which could be due in part to variations in the root system compared to bread wheats. Nogal is a synthetic wheat derived from crossing between durum wheat and Aegilops tauschii Coss., parents of present bread wheat. The experimental design was a randomized complete block with three replications. The area of each experimental plot was $9.5 \times 6.6 \mathrm{~m}^{2}$. On this site, wheat was grown after one year of durum wheat.

\subsection{Crop Management}

Wheat cultivars were sown on 28 October 2014 after ploughing $(25 \mathrm{~cm})$ and preparing the seed bed by disc harrowing and tilling with a vibrating tine cultivator. Plots were harvested on 1 July 2015. The four studied varieties were planted in $17.5 \mathrm{~cm}$ inter-rows at 300 grains per $\mathrm{m}^{2}$. During the wheat growing season, weed control was performed by aspersing four herbicides three times and fungicides were applied twice at flag leaf ligule and anthesis. Irrigation was applied on $\mathrm{I}+\mathrm{N}+$ and $\mathrm{I}+\mathrm{N}$ - treatments six times totalizing $189 \mathrm{~mm}$, while the rainfed plots received no irrigation. Nitrogen fertilizer was applied at four different rates depending on irrigation: $\mathrm{I}+\mathrm{N}+\left(230 \mathrm{~kg} \mathrm{ha}^{-1}\right.$, four applications); I + N-, (100 kg ha ${ }^{-1}$, two applications); I - N+ (150 kg ha ${ }^{-1}$ three applications) and $\mathrm{I}-\mathrm{N}-\left(50 \mathrm{~kg} \mathrm{ha}^{-1}\right.$, one application).

\subsection{Shoot Biomass and N Measurements}

Variations in shoot dry mass and nitrogen content of plants were determined at different growth stages. The growth stages of wheat were estimated using the Zadoks scale [28] and destructive plant measurements were done at two unfolded leaf (Z12), stem elongation (Z30), flag leaf ligule (Z39), anthesis half-way (Z65) and ripening (Z91). Shoot biomass was sampled from a $0.70 \mathrm{~m}^{2}$ area in each plot. Fresh and dry shoot mass were measured on an electronic scale and dry biomass was obtained by oven-drying at $80^{\circ} \mathrm{C}$ for $48 \mathrm{~h}$. The nitrogen content of shoot was measured by collecting two samples of plant material from the $0.7 \mathrm{~m}^{2}$ area. The level of nitrogen deficit was calculated with the nitrogen nutrition index (NNI, in \%) for winter wheat [29]. The wheat grain yield (GY15, in tha ${ }^{-1}$ ) determined at $15 \%$ moisture content was estimated on $9.5 \times 1.225 \mathrm{~m}^{2}$ by using a combine harvester (ZURN 150).

\subsection{Root Measurements}

\subsubsection{Minirhizotron Installation}

Root imaging from minirhizotrons was performed with the CI-600 root scanner (CID Bio-Science, Camas, WA, USA), controlled by a laptop computer. The size of the recorded images was $21.59 \mathrm{~cm} \times$ $19.56 \mathrm{~cm}$, with a 300-dpi resolution. Minirhizotron tubes were clear acrylic glass tubes of $2.0 \mathrm{~m}$ length, $6.3 \mathrm{~cm}$ inner diameter and $7.0 \mathrm{~cm}$ outer diameter. Minirhizotron tubes were inserted into the soil of the central sowing line of each plot a couple of days after sowing, at plant emergence (Figure 1b,c). 
Tubes were installed at a $45^{\circ}$ angle from horizontal. To minimize soil disturbance and to achieve a soil-tube contact as good as possible, soil drilling was performed using a $7 \mathrm{~cm}$ diameter auger operated slowly manually and affixed to a rigid self-made $45^{\circ}$ drilling frame. Tubes were inserted to a maximum vertical depth of $122 \mathrm{~cm}$, depending on the depth of the gravel layer. The above-ground part of each tube was covered with thermal insulation foils, to prevent light, condensation and sun warming of the tube. Images were captured at tillering (Z25), stem elongation (Z30), flag leaf ligule (Z39) and anthesis half-way (Z65).

\subsubsection{Image Processing of Minirhizotron Images}

The images were processed using the Smartroot software [30]; root length and root diameter were measured on every image (Figure 1d). Root length surface density along the tube (TRLSD, in $\mathrm{mm} \mathrm{cm}^{-2}$ ) was computed for each tube, according to their actual length over the tube surface area. The mean root length surface density profiles, for each wheat variety and treatment, were obtained by averaging replicate RLSD profiles. Before averaging the RLSD profiles, an interpolation was performed using a cubic Hermite spline in order to get the RLSD values at the same soil depths.

\subsubsection{Auger Sampling for Root Biomass}

An auger (40 mm diameter) was used to collect two soil samples in the central row of each plot, and a third soil sample in the middle of the nearby inter-row at tillering (Z25), stem elongation (Z30), flag leaf ligule (Z39) and anthesis half-way (Z65). Central rows were sampled at $10-20 \mathrm{~cm}$ and $30-40 \mathrm{~cm}$ depth, and inter-rows were sampled at $30-40 \mathrm{~cm}$. Roots were washed from the soil for $10 \mathrm{~min}$ using a hydropneumatic elutriator, collected on $350 \mu \mathrm{m}$ sieves, oven-dried at $70^{\circ} \mathrm{C}$ for $48 \mathrm{~h}$, and then weighted. For each plot, the total root biomass from the soil surface to $40 \mathrm{~cm}$ depth was calculated by assuming biomass at $10-20 \mathrm{~cm}$ depth equals biomass from $0-10 \mathrm{~cm}$ and with linear interpolation of root biomass at $20-30 \mathrm{~cm}$ depth. The root dry mass density over $0-40 \mathrm{~cm}$ depth $\left(R D M_{\mathrm{a}}, \mathrm{g} \mathrm{m}^{-2}\right)$ is estimated by:

$$
R D M_{a}=2 \times M_{h 1}+\frac{M_{h 2}+M_{h 2 i}+2 \times M_{h 1}}{4}+\frac{M_{h 2}+M_{h 2 i}}{2}
$$

where $M_{h 1}$ is the mean root biomass of 10-20 cm samples from the central row, $M_{h 2}$ is the mean root biomass of $30-40 \mathrm{~cm}$ samples from the central row, $M_{h 2 i}$ is the mean root biomass of $30-40 \mathrm{~cm}$ samples from the inter-row.

\subsubsection{Conversion of Root Length Surface Density to Root Biomass}

For converting root length surface density data from images to root biomass, we assumed that the soil volume sampled by the minirhizotron is a cylindrical shell. The inner radius of the shell is the tube outer radius and its thickness $(\varepsilon)$ is the image depth-of-field (DOF) of view of the scanner (Figure 3). This assumption implies that the root density measured in this soil volume sampled by the minirhizotron is the same as the root density measured in an extracted soil core.

Therefore, the relation between root length surface density measured over the minirhizotron surface $\left(R L S D\right.$, in $\left.\mathrm{mm} \mathrm{cm}^{-2}\right)$ and root biomass $\left(M_{\text {root }}\right.$, in $\left.\mathrm{g} \mathrm{m}^{-2}\right)$ observed over the same soil thickness $(\Delta z$, in $\mathrm{m})$ for coring and minirhizotron tube, inserted into the soil at a specific angle ( $\varphi$, in radian) is given by:

$$
M_{\text {root }}=\frac{R L S D}{\varepsilon \times S R L} \times \Delta z \times \cos (\varphi)
$$

where $S R L$ denotes the specific root length $\left(\mathrm{m} \mathrm{g}^{-1}\right)$. The values of the product $\varepsilon \times S R L$ were obtained by using minirhizotron and soil sampling data of samples from soil layer at $30-40 \mathrm{~cm}$ depth. The median $\left(\mu_{1 / 2}\right)$ value of $\varepsilon$ is calculated using the mean specific root length observed in situ for winter wheat crops, i.e., $S R L=180 \mathrm{~m} \mathrm{~g}^{-1}$ [30].

Alternative approaches for converting root length surface density obtained by minirhizotron into equivalent cored values exist. A similar method of calibration used a zero-intercept linear 
regression [31] instead of the distribution of conversion factors, while other approaches rely on the maximum diameter of observed roots as DOF [32].

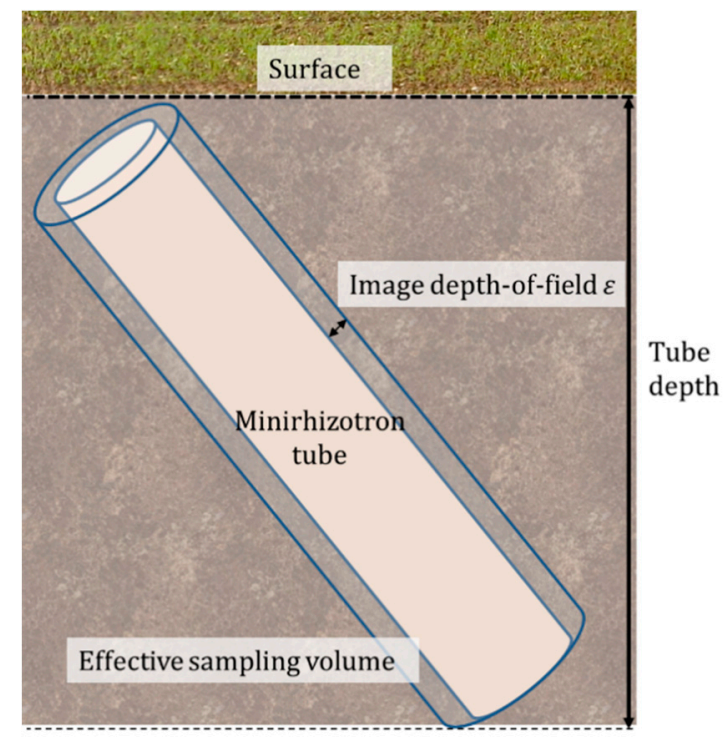

Figure 3. Principle of the conversion of root length surface density into root biomass. The minirhizotron tube is surrounded by the effective sampling volume considered for the conversion of root length densities to root biomasses. This effective sampling volume, represented by a blue shade, is a cylindrical shell of inner radius equals to the tube outer radius and of thickness $\varepsilon$, i.e., the image depth-of-field acquired by the scanner-based minirhizotron.

\subsection{Root to Shoot Ratio}

The root to shoot ratio (R:S) was calculated at tillering (Z25), stem elongation (Z30), flag leaf ligule (Z39) and anthesis half-way (Z65) as the ratio between the total root dry mass (RDM, in tha ${ }^{-1}$ ) and the shoot dry mass (SDM, in tha ${ }^{-1}$ ). The total root mass was computed as the sum of the root biomass estimated from auger sampling $\left(\mathrm{RDM}_{\mathrm{a}}\right.$, in $\left.\mathrm{g} \mathrm{m}^{-2}\right)$ and the minirhizotron root length measurements converted into root biomass $\left(\mathrm{RDM}_{\mathrm{m}}\right.$, in $\left.\mathrm{g} \mathrm{m}^{-2}\right)$. To prevent the overlapping of auger samples over the 0-40 cm depth with minirhizotrons that measure over the 0-100 $\mathrm{cm}$ depth, the root biomass estimated from minirhizotron measurements $\left(\mathrm{RDM}_{\mathrm{m}}\right)$ was restricted to depths deeper than $40 \mathrm{~cm}$ (Equation (3)).

$$
R D M=R D M_{a}+R D M_{m} \forall z>40 \mathrm{~cm}
$$

\subsection{Statistical Analyses}

An analysis of variance (ANOVA) with a mixed linear effect model of grain yield (GY15), shoot dry mass (SDM) and root dry mass (RDM) was calculated using MATLAB. Genotype (G), nitrogen treatment $(\mathrm{N})$ and irrigation treatment $(\mathrm{I})$ were considered as fixed effect, and replicates were considered as random effect. The means of the minirhizotrons depth (due to soil depth variations) were compared using the Fischer's least significant difference test at 0.05 probability level. The correlations between the different root and shoot variables were computed with MATLAB, along with p-values of the slope of the regression line. Coefficient of determination values $\left(r^{2}\right)$ were calculated using the squared Pearson product-moment correlation coefficient.

The $\alpha<0.05$ confidence interval for the median of the conversion factor $\left(\mu_{1 / 2}\right)$ for RLSD to biomass $(\varepsilon \times S R L)$ and for the mean of the root to shoot ratio (R:S) at the four growth stages, namely tillering (Z25), stem elongation (Z30), flag leaf ligule (Z39) and anthesis half-way (Z65), were computed using a non-parametric bootstrap with 100,000 paired sampled, drawn from the experimental pairs with replacement. The $\alpha / 2$ and 1- $\alpha / 2$ quantiles of the bootstrapped distribution of $\mu_{1 / 2}$ and of R:S were considered for the limits of the confidence interval. 


\section{Results}

\subsection{Root Length to Biomass Conversion Factor and Root to Shoot Ratio}

The median value of the distribution of the root length to biomass factor $(\varepsilon \times S R L)$ is $\mu_{1 / 2}=$ $0.61 \mathrm{~m}^{2} \mathrm{~g}^{-1}$ and the $95 \%$ confidence interval is $(0.50,0.73)$. The distribution of the conversion factor $(\varepsilon \times S R L)$, required to transform minirhizotrons data into equivalent root mass samples, from root data collected in the depth of 30-40 cm is shown in Supplementary Figure S2. Assuming an SRL value of $180 \mathrm{~m} \mathrm{~g}^{-1}$ [33], constant along the rooting depth [31], we estimate a median value of the depth-of-field of view $\varepsilon$ of the scanner-based minirhizotron equals to $3.5 \mathrm{~mm}$, ranging from 2.8 to $4.1 \mathrm{~mm}$ for the $95 \%$ confidence interval.

Using the median value of the conversion factor, the RLSD estimated by minirhizotron imaging is converted into root mass and enables the calculation of the root to shoot ratio (R:S). The dynamic of the root to shoot ratio averaged over each sampled plot is presented in Figure 4. The R:S values decrease from 0.66 , at tillering $(\mathrm{Z} 25)$, to 0.13 , at anthesis (Z65) with a dispersion that decreases from vegetative to latter stages (Z39, Z65). The obtained R:S values are close to the R:S ratio used in APSIM, a crop and agricultural system model [34], and show the consistency of the proposed root estimation approach.

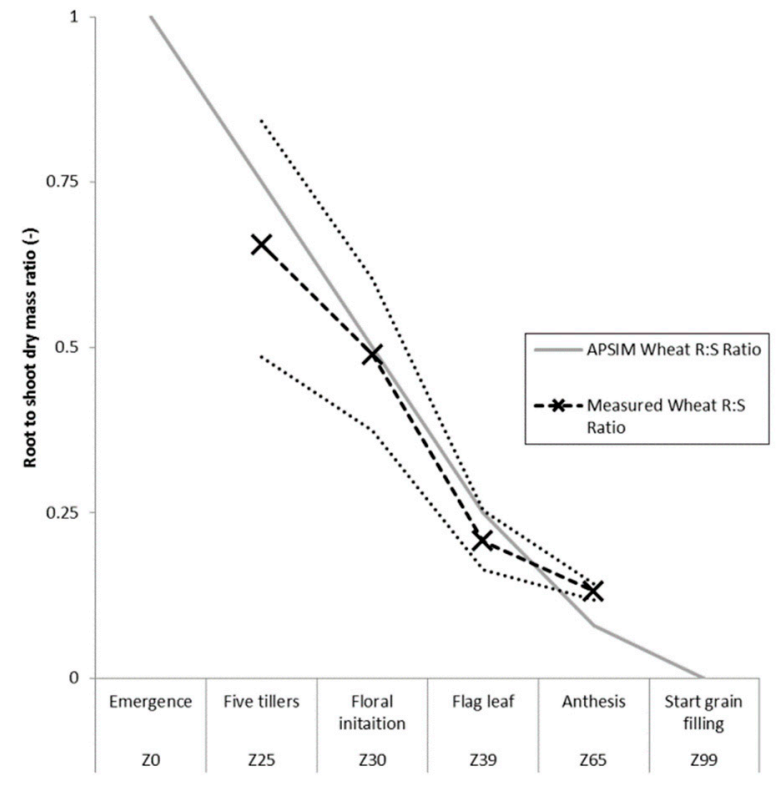

Figure 4. Dynamic of the root to shoot ratio (R:S) of wheat obtained with minirhizotron. The average root to shoot ratio $(x)$ is presented with the confidence interval at $95 \%$ level (dashed lines). The solid grey line is the R:S ratio used for modelling wheat growth in the APSIM model. Root biomass results from the summation of the two different root sampling techniques, i.e., auger and minirhizotron sampling. Data are obtained for tillering (Z25), stem elongation (Z30), flag leaf ligule (Z39) and anthesis half-way (Z65).

\subsection{Root Length Surface Density and Grain Yield}

The correlation between grain yield and measured root length surface density averaged on the whole length of minirhizotron tubes (TRLSD) is shown Figure 5. Grain yields range from $4.2 \mathrm{t} \mathrm{ha}^{-1}$ to $11.0 \mathrm{tha}^{-1}$, and the TRLSD from $3.0 \mathrm{~mm} \mathrm{~cm}^{-2}$ to $12.6 \mathrm{~mm} \mathrm{~cm}^{-2}$, with the highest yields and the highest root length densities occurring in the irrigated plots. Grain yield increases with TRLSD $\left(r^{2}=0.48\right.$, $p<0.001)$. This linear correlation considers only tubes located in a deep soil zone where the tubes' average depth is $98 \mathrm{~cm}$. All of the TRLSD measured in the shallow tubes are displayed on Figure 5 by red squares. Notably, all minirhizotron tubes of I $+\mathrm{N}-$ group $(n=4)$ are shallow because of the limited soil depth, and all lie outside the $\alpha<0.05$ confidence interval of the regression between average TRLSD and grain yield. 


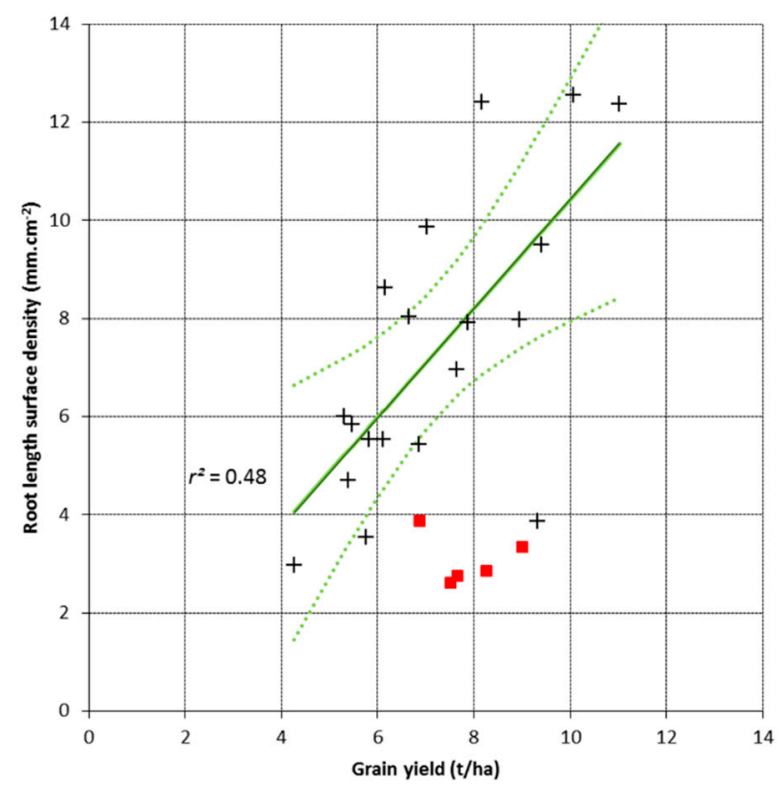

Figure 5. Correlation between wheat cultivars' grain yield $\left(\mathrm{t} \mathrm{ha}^{-1}\right)$ and total root length surface density $\left(\mathrm{mm} \mathrm{cm}^{-2}\right)$ at anthesis stage (Z65). Scatterplot and regression line with 95\% confidence band are shown for deep minirhizotron tubes (depth $>40 \mathrm{~cm}, n=19$ ) are shown. Data of the shallow minirhizotron tubes (depth $<40 \mathrm{~cm}, n=5$ ) are displayed as red dots. The equation of the regression line is $\mathrm{y}=1.1 \mathrm{x}-0.7$.

\subsection{Impact of Different $N$ and Water Treatments}

Table 1 displays grain yield, and values at anthesis (Z65) of shoot dry mass (SDM), root dry mass (RDM), and root to shoot ratio (R:S). Data are the average of three plots in the case of grain yield and 2 plots in the case of SDM, RDM and R:S. In irrigated conditions, average grain yields range from 9.32 to $8.16 \mathrm{tha}^{-1}$ in $\mathrm{I}+\mathrm{N}+$ and $\mathrm{I}+\mathrm{N}-$, respectively, while in rainfed conditions, average grain yield is lower and ranges from 5.62 to $6.67 \mathrm{t} \mathrm{ha}^{-1}$ in $\mathrm{I}-\mathrm{N}+$ and $\mathrm{I}-\mathrm{N}-$, respectively. The ANOVA was performed on these variables for the whole experimental field (shallow soil conditions included), and the different irrigation treatments (irrigated conditions and rainfed conditions). A significant effect on grain yield of the irrigation treatment, the genotype and interactions between fertilization and irrigation (both $p$-value $<0.001)$ is revealed.

Table 2 shows the results of the analysis of variance (ANOVA) performed on grain yield (GY15), and shoot dry mass (SDM), root dry mass (RDM) and root to shoot ratio (R:S) measured at anthesis (Z65). Fertilization has no significant effect on grain yield, unlike shoot dry mass, root dry mass and R:S ratio ( $p$-values $<0.01$ ). ANOVA results from rainfed conditions show a statistically significant effect of fertilization on grain yield and R:S ratio ( $p$-value $<0.001$ and $<0.01$, respectively), while no significant effect has been found on shoot dry mass and root dry mass. In addition, a significant interaction of genotype $\times$ fertilization on root dry mass and R:S ratio ( $p$-value $<0.001$ and $<0.01$, respectively) is evidenced in rainfed conditions. 
Table 1. Irrigation and Nitrogen (I, N) treatments effect on root and shoot variables of wheat cultivars at anthesis. The table shows the mean values of plots at anthesis of shoot dry mass (SDM, $\mathrm{tha}^{-1}$ ), root dry mass (RDM, $\mathrm{t} \mathrm{ha}^{-1}$ ) and root to shoot ratio (R:S, dimensionless), and the grain yield (GY15, $\mathrm{tha}^{-1}$ ) at harvest.

\begin{tabular}{|c|c|c|c|c|c|}
\hline Treatment & Genotype & GY15 (t ha-1) & SDM (t ha $\left.{ }^{-1}\right)$ & RDM (t ha-1) & $\mathrm{R}: \mathrm{S}(-)$ \\
\hline \multirow[t]{4}{*}{$\mathrm{I}+\mathrm{N}+$} & Miradoux & 8.79 & 10.53 & 1.56 & 0.15 \\
\hline & Apache & 9.04 & 10.85 & 1.24 & 0.11 \\
\hline & Hystar & 10.33 & 11.84 & 1.67 & 0.14 \\
\hline & Nogal & 9.12 & 11.02 & 1.48 & 0.13 \\
\hline Mean I + N+ & & 9.32 & 11.06 & 1.49 & 0.13 \\
\hline \multirow[t]{4}{*}{$\mathrm{I}+\mathrm{N}-$} & Miradoux & 7.12 & 8.22 & 0.88 & 0.11 \\
\hline & Apache & 8.31 & 8.21 & 0.96 & 0.12 \\
\hline & Hystar & 9.87 & 9.75 & 0.91 & 0.09 \\
\hline & Nogal & 7.34 & 8.32 & 1.08 & 0.13 \\
\hline Mean I + N- & & 8.16 & 8.62 & 0.96 & 0.11 \\
\hline \multirow[t]{4}{*}{$\mathrm{I}-\mathrm{N}+$} & Miradoux & 4.91 & 8.30 & 1.13 & 0.14 \\
\hline & Apache & 5.19 & 9.89 & 1.10 & 0.11 \\
\hline & Hystar & 6.26 & 9.24 & 1.05 & 0.11 \\
\hline & Nogal & 6.14 & 9.25 & 0.80 & 0.09 \\
\hline Mean I - N+ & & 5.62 & 9.17 & 1.02 & 0.11 \\
\hline \multirow[t]{4}{*}{$\mathrm{I}-\mathrm{N}-$} & Miradoux & 5.79 & 7.50 & 0.91 & 0.12 \\
\hline & Apache & 7.17 & 9.06 & 1.39 & 0.15 \\
\hline & Hystar & 7.65 & 8.26 & 1.29 & 0.16 \\
\hline & Nogal & 6.06 & 8.42 & 1.25 & 0.15 \\
\hline Mean I - N- & & 6.67 & 8.31 & 1.21 & 0.14 \\
\hline
\end{tabular}

Table 2. Analysis of variance (ANOVA) of the Irrigation and Nitrogen (I, N) treatments for wheat cultivars on the measured variables (Yield: GY15, Shoot dry mass at anthesis: SDM, Root dry mass at anthesis: RDM, Root/shoot ratio at anthesis: R:S) for the four different treatments.

\begin{tabular}{|c|c|c|c|c|c|}
\hline Treatment & & GY15 (t ha-1) & $\operatorname{SDM}\left(\mathrm{t} \mathrm{ha} \mathrm{a}^{-1}\right)$ & $\operatorname{RDM}\left(\mathrm{t} \mathrm{ha} \mathrm{a}^{-1}\right)$ & $\mathrm{R}: \mathrm{S}(-)$ \\
\hline \multirow[t]{6}{*}{ Source of variance } & Fertilization & NS & $* *$ & $* *$ & $* *$ \\
\hline & Irrigation & $* * *$ & NS & NS & NS \\
\hline & $\mathrm{G} \times \mathrm{N}$ & $* *$ & NS & $* *$ & . \\
\hline & $\mathrm{G} \times \mathrm{I}$ & . & . & . & $* * *$ \\
\hline & $\mathrm{N} \times \mathrm{I}$ & $* * *$ & * & $* * *$ & $* * *$ \\
\hline & Genotype & * & NS & $* *$ & NS \\
\hline \multirow[t]{3}{*}{ Irrigated conditions } & Fertilization & NS & * & * & NS \\
\hline & $\mathrm{G} \times \mathrm{N}$ & NS & NS & * & . \\
\hline & Genotype & NS & . & NS & * \\
\hline \multirow[t]{2}{*}{ Rainfed conditions } & Fertilization & $* * *$ & NS & . & $* *$ \\
\hline & $\mathrm{G} \times \mathrm{N}$ & * & NS & $* * *$ & $* *$ \\
\hline
\end{tabular}

Variation of Nitrogen nutrition index (NNI), mean root length surface density over minirhizotron tubes (TRLSD) and maximum depth of minirhizotrons between the four treatments is shown Table 3 . NNI of $\mathrm{N}$ deprived treatments $(\mathrm{I}+\mathrm{N}-$ and $\mathrm{I}-\mathrm{N}-$ ) are not significantly different but differ from other treatments resulting in three different groups (Fischer test, $p<5 \%$ ). When excluding the zone of shallow soil of minirhizotron installation, excluding the I + N- treatment, the other treatments do not differ in terms maximum depth of minirhizotron tubes. Mean root length densities over the minirhizotron 
depth were analysed at anthesis (Z65) only for those tubes of sufficient depths. The average TRLSD measurements at anthesis range from $4.3 \mathrm{~mm} \mathrm{~cm}^{-2}$ to $9.5 \mathrm{~mm} \mathrm{~cm}^{-2}$, similar to TRLSD measured in a previous experiment [26].

Table 3. Statistical analysis of the soil-related variables for the 4 different Irrigation and Nitrogen (I, N) treatments. The table shows the plot mean values of the nitrogen nutrition index (NNI, \%) at flag leaf ligule (Z39) and at anthesis (Z65) stages, the minirhizotron tubes' mean values of the root length surface density (TRLSD in $\mathrm{mm} \mathrm{cm}^{-2}$ ) and the maximum tube insertion depth $(\mathrm{cm})$. Standard errors are presented in parentheses, and the sample size is denoted by $n$. Values followed by different letters are statistically different $(p<0.05)$. NA: Data not available.

\begin{tabular}{|c|c|c|c|c|c|c|c|c|}
\hline & $\begin{array}{c}\text { NNI } 20 \text { April } 2015 \\
\text { (Z39) }\end{array}$ & & $\begin{array}{l}\text { NNI } 10 \text { May } 2015 \\
\text { (Z65) }\end{array}$ & & $\begin{array}{l}\text { TRLSD (mm } \\
\left.\mathrm{cm}^{-2}\right)\end{array}$ & & $\begin{array}{l}\text { Minirhizotron } \\
\text { Max. Depth (cm) }\end{array}$ & \\
\hline & Mean & $n$ & Mean & $n$ & Mean & $n$ & Mean & $n$ \\
\hline $\mathrm{I}+\mathrm{N}+$ & $1.19(0.17) \mathrm{c}$ & 8 & $1.25(0.13) \mathrm{c}$ & 8 & $9.5(3.0) \mathrm{a}$ & 7 & 95 (16) a & 7 \\
\hline $\mathrm{I}+\mathrm{N}-$ & $0.84(0.16) \mathrm{a}$ & 8 & $0.85(0.23)$ a & 8 & NA & NA & $45(8) b$ & 4 \\
\hline $\mathrm{I}-\mathrm{N}+$ & $0.98(0.13) b$ & 8 & $1.03(0.12) \mathrm{b}$ & 8 & $4.3(1.6) \mathrm{b}$ & 4 & $96(21) \mathrm{a}$ & 4 \\
\hline $\mathrm{I}-\mathrm{N}-$ & $0.77(0.09) \mathrm{a}$ & 8 & $0.70(0.05) \mathrm{a}$ & 8 & $7.2(1.8) a b$ & 8 & $106(15) \mathrm{a}$ & 8 \\
\hline
\end{tabular}

\subsection{Variation of the RLSD under the Different Water, $N$ Treatments}

The RLSD profiles of Apache cultivar in I + N+, I - N+ and I - N- treatments, at tillering (Z25), stem elongation (Z30), flag leaf ligule (Z39) and anthesis half-way (Z65) are shown Figure 6. Differences in RLSD profiles between treatments appeared at stem elongation stage, which started on March 24. At flag leaf ligule stage, RLSD profiles are mostly close to their maximal growth occurring at anthesis.

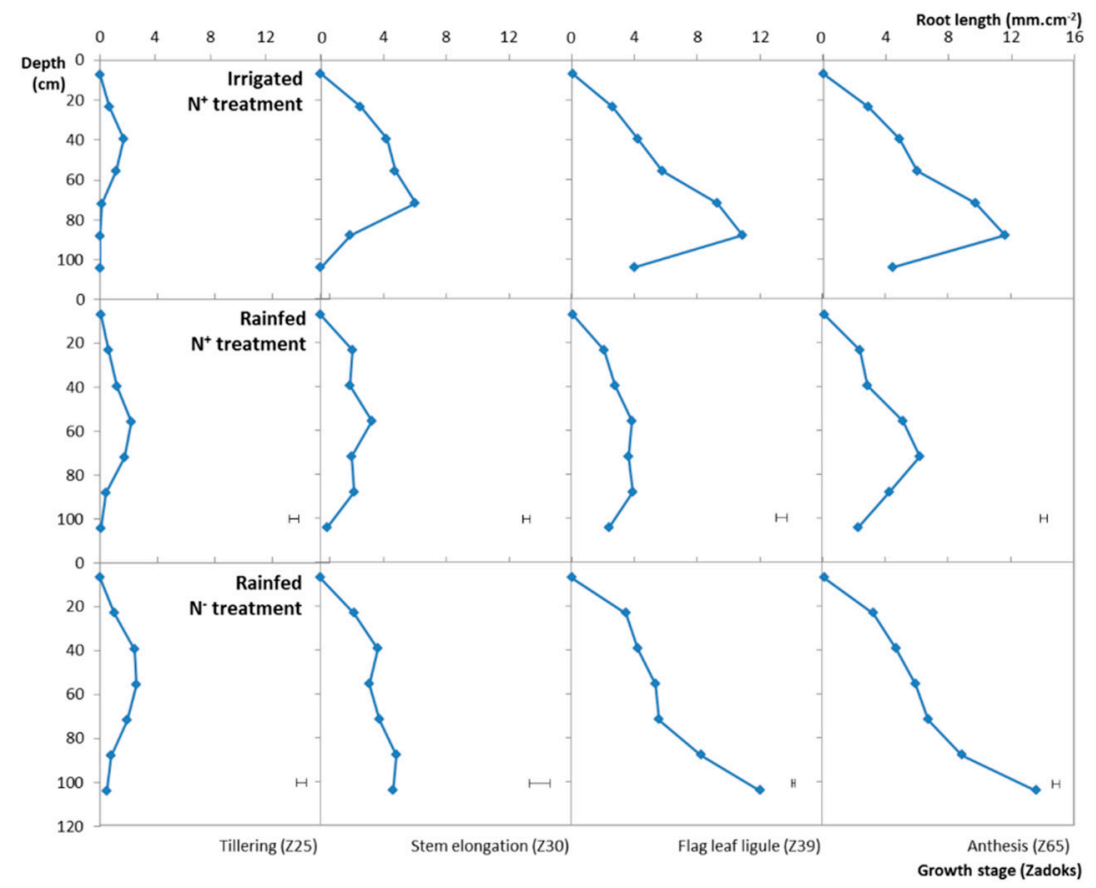

Figure 6. Treatments effects (Irrigation, Nitrogen) on the root length surface density profiles' dynamic of the Apache bread wheat. The mean RLSD profiles $\left(\mathrm{mm} \mathrm{cm}^{-2}\right)$ of Apache wheat cultivar are shown at tillering (Z25), stem elongations (Z30), flag leaf ligule (Z39) and anthesis (Z65) stages, with bars representing the median variation of RLSD. Fertilised plots in rainfed conditions $(\mathrm{I}-\mathrm{N}+$ ) display shallow root profiles, whereas I - N- plots exhibit a root system that developed deeper. The latter yielded $1.9 \mathrm{t} \mathrm{ha}^{-1}$ more than its counterpart under $\mathrm{I}-\mathrm{N}+$ conditions. 
All RLSD profiles display a decrease of, and low, root density in the top soil layers. Similar biases were reported on graminaceous species [35-37], and in our $45^{\circ}$ angle-oriented tubes, the bias could be due to the illumination of the top of the tubes, as also observed in prior experiments [27].

Compared to the I - N+ treatment, I + N+ and I $-\mathrm{N}-$ treatments result in higher values of RLSD in the deep layers of soil $(>60 \mathrm{~cm})$. Root length surface density profiles for $\mathrm{I}+\mathrm{N}+$ displays a maximum at $88 \mathrm{~cm}$ depth and then a decrease, whereas RLSD profiles at I - N- show a continuous increase over the depth of the minirhizotron tubes.

Figure 7 shows the same plot of RLSD profiles for the durum wheat cultivar Miradoux. Similarly, the root system appears less developed under the I - N+ than under other conditions, with low values in deeper soil layers $(>40 \mathrm{~cm})$ reaching at maximum $4.5 \mathrm{~mm} \mathrm{~cm}^{-2}$. In contrast to the Apache cultivar, no continuous increase of RLSD occurs in I $+\mathrm{N}+, \mathrm{I}-\mathrm{N}-$ and RLSD shows a pic at $\sim 70 \mathrm{~cm}$ depth. For Miradoux, the differentiation between treatment rises early as tillering (Z25).

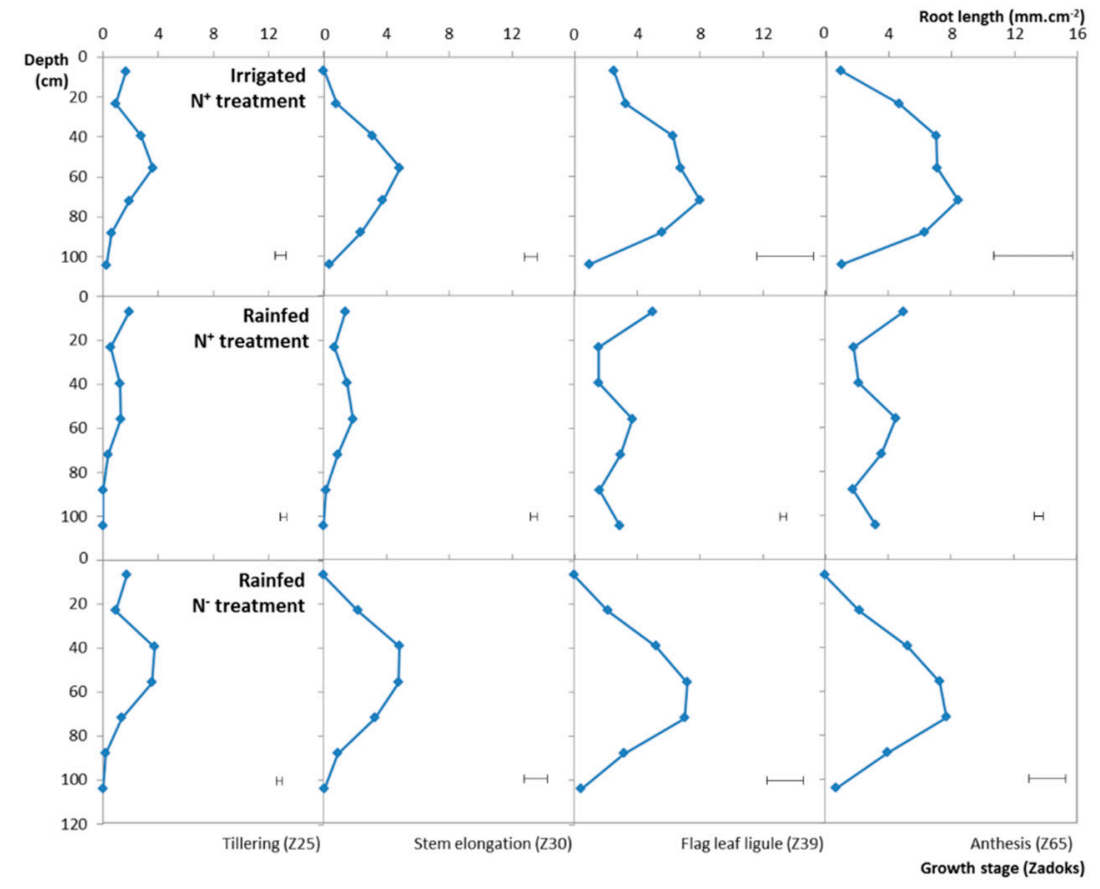

Figure 7. Treatments effects (Irrigation, Nitrogen) on the root length surface density profiles' dynamic of the Miradoux durum wheat. The mean RLSD profiles $\left(\mathrm{mm} \mathrm{cm}^{-2}\right)$ of Miradoux wheat cultivar are shown at tillering (Z25), stem elongations (Z30), flag leaf ligule (Z39) and anthesis (Z65) stages, with bars representing the median variation of RLSD. Globally, root profiles obtained under all conditions are shallow, their maximum of RLSD occurring above $80 \mathrm{~cm}$ depth followed by a rapid decrease. At harvest, the mean grain yield difference between $\mathrm{I}-\mathrm{N}+$ and $\mathrm{I}-\mathrm{N}-$ is $0.92 \mathrm{t} \mathrm{ha}{ }^{-1}$, smaller than the one obtained for the bread wheat Apache cultivar.

The two other cultivars (Nogal, Hystar) were measured with minirhizotron only under extreme opposite conditions (i.e., I + N+ and I - N-). Their RLSD plots are displayed in Supplementary Figures S3 and S4. The Hystar cultivar-a hybrid wheat of bread wheat Apache ascent-is comparable to Apache rooting pattern under the both treatments. In contrast, the Nogal cultivar, a synthetic wheat, shows two different patterns, similar to Apache cultivar under I + N+ and related to Miradoux cultivar under I - N-. The superposition of the four RLSD profiles under I - N- conditions is presented in Supplementary Figure S5.

\subsection{Allometric Relation between Plant Traits}

Figure 8 shows the relations between different plant traits at anthesis, including grain yield. Irrigated and rainfed conditions data are separated for regression. Coefficient of determination between 
yield and shoot dry mass (SDM) is $r^{2}=0.6$ in irrigated conditions, while no correlation arises $\left(r^{2}=0.02\right)$ from plots in rainfed conditions (Figure 8a). Similarly, shoot dry mass (SDM) and root dry mass (RDM) show a correlation in irrigated conditions $r^{2}=0.46$ which breaks down in rainfed conditions $\left(r^{2}=0.00\right.$, Figure $8 b)$. Root dry mass (RDM) and grain yield are correlated neither in irrigated conditions nor in rainfed conditions (Figure 8c). In opposite, deep root length surface density (TRLSD) is highly correlated to grain yield in rainfed conditions $\left(r^{2}=0.41\right)$ unlike plots in irrigated conditions $\left(r^{2}=0.02\right.$, Figure $8 d$ ).
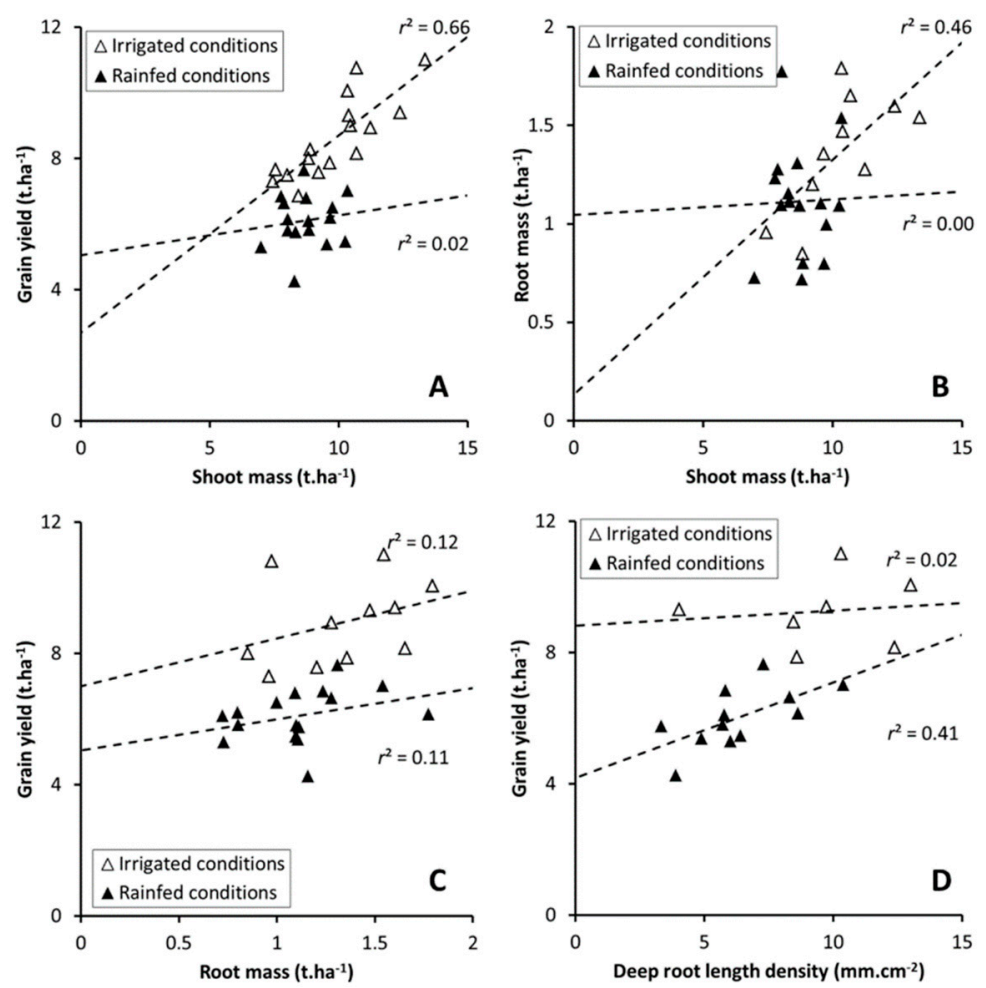

Figure 8. Relations between aerial traits and underground traits for wheat varieties. Correlations between shoot mass $\left(\mathrm{t} \mathrm{ha}^{-1}\right)$ and grain yield $\left(\mathrm{t} \mathrm{ha}^{-1}\right)(\mathbf{A})$, shoot mass $\left(\mathrm{t} \mathrm{ha}^{-1}\right)$ and root mass $\left(\mathrm{t} \mathrm{ha}^{-1}\right)(\mathbf{B})$, root mass $\left(\mathrm{t} \mathrm{ha}^{-1}\right)$ and grain yield $\left(\mathrm{t} \mathrm{ha}^{-1}\right)(\mathbf{C})$, deep root length density $\left(\mathrm{mm} \mathrm{cm}^{-2}\right)$ and grain yield $\left(\mathrm{t} \mathrm{ha}^{-1}\right)(\mathbf{D})$, at anthesis $(\mathrm{Z} 65)$, in irrigated $(\Delta)$ and rainfed $(\boldsymbol{\Delta})$ conditions. Determination coefficients are displayed on top right corner for irrigated and middle right for rainfed conditions. Since no correlation can be found between grain yield and shoot biomass under rainfed conditions, grain yield cannot be assessed from plant aerial characteristics before harvesting. In contrast, deep root length surface density is highly correlated to grain yield in rainfed conditions.

\section{Discussion}

\subsection{Minirhizotron Methodology Reliability}

The conversion of the minirhizotrons data to actual root mass is a complex problem, and the most straightforward solution is to consider an equivalent sampling volume. In our case, the conversion factor value proposed in our study appears to be in agreement with the depth-of-field previously estimated [31,38] at $2-3 \mathrm{~mm}$. We found a close depth-of-field value $(\varepsilon=0.35)$ using the mean SRL value for winter wheat crop cultivars [33]. However, SRL was not specifically measured, and higher values of SRL would lead to smaller DOF, and vice versa.

The heavy-tailed skewedness distribution of the conversion factor (Supplementary Figure S2) is a result from the outliers in the RLSD measurements or from the auger sampling of root mass, producing high values of $\varepsilon \times \mathrm{SRL}$. Thus, the median of the distribution is preferred to the mean in order to have a statistic robust to outliers. 
Our linearly estimated sigmoid root biomass profile, coupled to minirhizotron measurements led to R:S values in the range of previous observations [39-41] at anthesis in different growth conditions. Moreover, the evolution with time of this R:S ratio is closely related to the R:S ratio used in crop growth modelling [34] (Figure 4).

Our methodology differs from previous studies, by being less prone to the influence of outliers. A common way to estimate this type of conversion factor is the use of a linear regression without $y$-intercept between minirhizotron data and gravimetric sampling data. However, linear regressions are not robust to outliers, and coupled with the loss of accuracy linked to the imposition of zero intercept, are not informative about the dispersion of this conversion factor. A robust linear estimator, as the Theil-Sen estimator used in agrophysics [42], could solve the issues related to outliers, but not concerns the y-intercept. The bootstrapping of the distribution of the individual conversion values has intrinsically a zero-intercept and allows for the computation of a non-parametric confidence interval. Hence, this methodology does not rely on assumption on the normality of the error, and hence is more suited for this type of calibration.

In spite of these advantages, this methodology could be challenged by the variations of the SRL found variable among cultivars, among growth conditions $[33,43]$, i.e., not constant as we assumed. As a consequence, our R:S values are only estimations. Nevertheless, the major contribution of the root mass is given by the top layers root system, reducing the weight of the error on the estimation of root mass obtained by RLSD conversion of minirhizotron data.

It appears that top soil bias is a major issue linked to this minirhizotron technique and special attention must be provided. Even by covering the emerged part of tubes with insulating material, it seems that illumination of top tube eventually happens. This bias may also come from poor contact between soil and minirhizotron tube. Indeed, time for soil to settle back on tube can be rather long (i.e., $>6$ months $[38,44])$. In the case of annual crops, especially in micro-plots dedicated to phenotyping, it is nearly impossible to install the tubes well in advance because of agricultural operations (ploughing, sowing). In our study, the last measurement occurred ca. 6.5 months after tube installation. Despite the care given to adjust soil coring to tube diameter, the drilled hole was a little bit larger than the tube in the ploughed layer ( $25 \mathrm{~cm}$ depth), notably at depth $<10 \mathrm{~cm}$, probably participating to the measurement bias in the top soil. At a greater depth, the soil contact was better. The relationship established above between root mass from auger sampling and RLSD from scanner images also confirms that deep root scanner measurements were representative of the plot.

Presently, the major bottleneck of the technique resides in the absence of automatic image processing. Even if accurate algorithm exists for washed roots imaged with flat scanners, they appear not well suited for minirhizotrons images, as the heterogeneity of the background-the time-varying hue of the soil around the tube-prevents simple segmentation of roots. Nevertheless, minirhizotrons allow for repetitions of sampling without apparent field destruction, and thus give access to fine dynamics such as rooting speed, or senescence after anthesis. Moreover, the large surface of the sampling zone of scanner-based minirhizotron confers a relatively high accuracy.

\subsection{Effect of Multifactorial Stress on Grain Yield and Root System}

Water was found as the principal limiting factor, as yield gaps $(\Delta G Y)$ due to the different irrigation treatments were larger than the yield gaps due to nitrogen treatments (Table 1). Nonetheless, the combination of nitrogen and water stress occurring at different successive times produced a specific effect on grain yields: yields in I - N- were higher than yields in I - N+. In our field conditions, the stress due to water limitation occurred in early April, while deficiency in nitrogen took places in early January. This contrasts with results for yield obtained from experiments combining a permanent severe drought with nitrogen deficiency [21]. This counter-intuitive effect of multi-stress conditions is not related to a bad evaluation of nitrogen input [17], as supported by the NNI data-NNI of N- plots was $<0.9$ whereas NNI of $\mathrm{N}+$ plots was $>0.9$ (Table 2) —even if plants from rainfed conditions display a significantly lower shoot nitrogen content. 
The root growth measured with minirhizotrons followed the assumed dynamics: differences in RLSD profiles arose when environment began to differ, i.e., at the beginning of nitrogen stress at the early Z30 stage. Root measurement performed with minirhizotrons showed that, at anthesis, root systems were deeper in $\mathrm{I}-\mathrm{N}-$, than in $\mathrm{I}-\mathrm{N}+$, which is actually an effect opposite to the consequence of a permanent severe water and nitrogen stress [21].

Moreover, the yield gaps $(\Delta G Y)$ between multi-stressed conditions $(\mathrm{I}-\mathrm{N}-)$ and optimal conditions $(\mathrm{I}+\mathrm{N}+)$ were smaller for the Apache bread wheat cultivar than for the Miradoux durum wheat cultivar $\left(\Delta \mathrm{GY}=1.87 \mathrm{tha}^{-1}\right.$ and $\Delta \mathrm{GY}=3 \mathrm{tha}^{-1}$, for Apache and Miradoux, respectively), illustrating the better adaption of bread wheat cultivars to a combination of constant nitrogen stress and late stage drought.

Along with this yield gaps, it appears that durum and bread wheat have two different rooting patterns, notably under sub-optimal growth conditions. Under these multi-stressed conditions (I - N-), the bread wheat cultivar (Apache) displayed deep root system, whereas the root system of the durum wheat cultivar (Miradoux) was shallower (Figures 6 and 7). The root density of the bread wheat cultivar didn't decrease before the bottom of the minirhizotron tubes, unlike durum wheat root systems which exhibited a significant decrease (Supplementary Figure S5).

Thus, this deeper root system provided higher drought tolerance by increasing the capacity to capture water located in deep soil layers [45] and, finally, grain yields of Apache were higher than Miradoux under these multi-stressed conditions $(\mathrm{I}-\mathrm{N}-)$.

The RLSD profiles appears to be cultivar dependent, and a parallel can be drawn between cultivars yield performance under multi-factorial stress and root architecture viewed through minirhizotrons, illustrated by the Supplementary Figures S3 and S4. The Hystar cultivar-hybrid cultivar of Apache ascent-showed a similar root system architecture to Apache under optimal conditions $(\mathrm{I}+\mathrm{N}+)$ and multi-stress conditions ( $\mathrm{I}-\mathrm{N}-$ ), denoting the same drought resistance traits than Apache, while a more complex relation ties the synthetic wheat cultivar (Nogal) and the durum wheat cultivar (Miradoux). The Nogal synthetic wheat cultivar produced the same root system architecture than bread wheat Apache cultivar under optimal conditions $(\mathrm{I}+\mathrm{N}+)$, whereas under multi-stress conditions ( $\mathrm{I}-\mathrm{N}-$ ) Nogal and Miradoux had comparable shallower root system architectures. Synthetic hexaploid wheats genotypes, developed to increase genetic variability in wheat, were not specifically screened for stress tolerance [46] and the Nogal cultivar rooting pattern may not be adapted to suboptimal conditions, unlike bread wheats.

However other root traits and their related physiological functions, such as the root diameter or the topology, were not considered, even if the latter has been found constant with depth for sole cropping wheat. Similarly, the precise water consumption estimated by carbon isotope discrimination or by soil water content variations, both not evaluated, could help us in determining the role of shoot or root traits in the drought resistance. Nonetheless, it appears that stay-green phenotypes do not display a significant reduction of soil moisture, and thus, relation between root length density and soil water content variations could be complex [47]. Nevertheless, the minirhizotron technique highly enhances the practicability of the estimation of root dynamics during the post-anthesis period, allowing direct and non-destructive access to the root system during its senescence.

\subsection{Relevance of Minirhizotron in Field Crop Trials}

In spite of the bias attached to the estimation with minirhizotron of the root system located in the shallow layers, we observed that TRLSD at anthesis has a great impact on grain yield $\left(r^{2}=0.48\right.$, Figure 5), regardless of treatments. A similar relation was observed on wheat crops with the same yield range $\left(5-11 \mathrm{t} \mathrm{ha}^{-1}\right)$, with a similar coefficient of determination $\left(r^{2}=0.56\right)$ [48], though with an older technique.

The tubes considered for the regression between grain yield and deep root length (Figure 8) were buried at a similar depth (Table 3), preventing effects related to soil depth, and thus considering only deep soil plots. Along with electrical resistivity mapping of the plots (Supplementary Figure S1), this confirms that the depth of silty loam soil was homogenous over the different plots. 
The relevance of minirhizotron measurements at anthesis was different considering the different irrigation treatment. Indeed, we observed that RLSD is notably correlated with the grain yield in rainfed conditions $\left(r^{2}=0.41\right.$, Figure $\left.8 \mathrm{~d}\right)$, whereas it shows no effect on grain yield in irrigated conditions $\left(r^{2}=0.00\right.$, Figure $\left.8 \mathrm{~d}\right)$. This relevance of deep soil measurement is illustrated by the absence of correlation between the root dry mass (the total mass of root located along the tube) and the grain yield regardless of treatment $\left(r^{2}=0.0 .12\right.$ and $r^{2}=0.11$ under irrigated and rainfed conditions, respectively), as shown in Figure $8 \mathrm{~b}$. This illustrates the dependence of the root length allocation on the treatment applied, and its implication on the grain yield in case of late drought.

Moreover, it is worth noting that in rainfed conditions, the shoot biomass and grain yield are not correlated, unlike in irrigated conditions (Figure 8a). In a similar way, in rainfed conditions the root mass does not correlate with above ground biomass, while the root mass could be estimated using the shoot mass in irrigated conditions. Thus, in our rainfed conditions, the above ground biomass at anthesis can give insights neither in the harvested grain yield nor in the drought tolerance.

However, since the minirhizotron technique was not reliable on shallow soil, the results are applicable for deep soil conditions only. Even if auger sampling compensates for this surface bias, the increase in shallow root densities $[20,22]$ remains inaccessible to minirhizotron measurements. Another point concerns the possible impact of the soil texture on the measurement bias. Soils rich in clay could lead to larger gaps around the minirhizotron tube near the surface, that could alternate the root growth, and thus induce another bias.

Finally, even if wheat plants traits at anthesis give large insights on final grain yield, post-anthesis dynamic also influences the final grain yield [49]. Nevertheless, the minirhizotron technique enables the estimation of rooting strategies and plasticity of plants non-destructively, making it a valuable tool for cultivar comparison and for improving the root part of models by in situ calibration.

\section{Conclusions}

For the conditions of a loamy Fluvisol in a Mediterranean climate, under irrigated and rainfed conditions, wheat root length surface density estimated with minirhizotrons at anthesis stage was highly correlated with the grain yield $\left(r^{2}=0.48\right)$. Moreover, under rainfed conditions, we observed that nitrogen stressed plots exhibited higher grain yields, in correlation with larger root systems in deep soil $\left(r^{2}=0.41\right)$ at anthesis, which were induced by a nitrogen deficiency occurring before drought. In spite of biases in root measurements with minirhizotrons in shallow soil, the minirhizotron technique provided rapid root length density estimations with the present non-parametric calibration methodology. The reliability of this calibration is supported by the estimated root to shoot ratio at the different growth stages. However, the processing of the minirhizotron images remains a major bottleneck, and substantial improvements in its automation would allow further exploitations of minirhizotron technique. Further studies are necessary to evaluate the contribution of minirhizotron in post-anthesis dynamics, which is also substantially linked to crop grain yield. Nevertheless, this technique would be a valuable tool for the determination of root traits of interest for drought resistance, and in enhancing accessibility to root measurement for crop breeding programs.

Supplementary Materials: The following is available online at http://www.mdpi.com/2073-4395/9/6/297/s1: Figure S1. Electrical resistivity $(\Omega \mathrm{m})$ map of the experimental field. Green areas denote low electrical values, and red areas denote high electrical values. Positions of minirhizotron tubes are displayed by white triangles $(\Delta)$. Low values of resistivity are related to deeper soils, whereas high values of resistivity are related to shallower soils. Using soil coring samples and minirhizotron depths, the scale relating depth to resistivity is estimated as follows: $29-78 \Omega \mathrm{m}=71-120 \mathrm{~cm}, 78-126 \Omega \mathrm{m}=40-70 \mathrm{~cm}, 126-175 \Omega \mathrm{m}=30-40 \mathrm{~cm}$, and 175-275 $\Omega \mathrm{m}<30 \mathrm{~cm}$. Figure S2. Histogram of the conversion parameter $(\varepsilon \times \mathrm{SRL})$ to a volumetric root biomass obtained with Equation (2). The median value of the conversion parameter is $\mu 1 / 2=0.62 \mathrm{~m}^{2} \mathrm{~g}^{-1}$, leading to a depth of field of view of $3.5 \mathrm{~mm}$ by considering a specific root length (SRL) value for winter wheat of to $180 \mathrm{~m} \mathrm{~g}^{-1}$. Figure S3. Effect of the Irrigation, Nitrogen (I, N) treatments on the dynamic of the Hystar hybrid bread wheat root length surface density profiles $\left(\mathrm{mm} \mathrm{cm}^{-2}\right)$ estimated from minirhizotron at different stages. Mean root length surface density profiles of the Hystar wheat cultivar are shown at tillering (Z25), stem elongations (Z30), flag leaf ligule (Z39) and anthesis (Z65) stages. Under the two treatments monitored (optimal and water and nutrient coupled stress), both 
exhibit a deep rooting profile pattern, optimal conditions peaking at $17.35 \mathrm{~mm} \mathrm{~cm}^{-2}$ at anthesis (out of figure). Figure S4. Effect of the Irrigation, Nitrogen (I, N) treatments on the dynamic of the Nogal synthetic wheat root length surface density profiles $\left(\mathrm{mm} \mathrm{cm}^{-2}\right)$ estimated from minirhizotron at different stages. Mean root length surface density profiles of the Nogal synthetic wheat cultivar are shown at tillering (Z25), stem elongations (Z30), flag leaf ligule (Z39) and anthesis (Z65) stages. Optimal and stressful conditions show contrasted rooting pattern. Under optimal conditions, this synthetic wheat cultivar exhibits a deep root profile, as measured for the bread wheat Apache cultivar. On the opposite, under stressful conditions, the root pattern developed is closer to the durum wheat Miradoux cultivar. Figure S5. Comparison of the root length surface density profiles obtained with minirhizotron technique at anthesis half-way (Z65) on average for each wheat cultivar under stressful conditions $(\mathrm{I}-\mathrm{N}-)$. Similarities are found between the rooting profiles of Apache and Hystar cultivars on the one hand, and Miradoux and Nogal cultivars on the other hand. A parallel may be drawn regarding their grain yield in this I $\mathrm{N}$ - treatment: higher yields being obtained by Apache and Hystar cultivars $\left(7.17 \mathrm{t} \mathrm{ha}^{-1}, 7.65 \mathrm{t} \mathrm{ha}^{-1}\right.$, respectively) and lower yields obtained by Miradoux and Nogal cultivars (5.79 $\mathrm{t} \mathrm{ha}^{-1}, 6.06 \mathrm{t} \mathrm{ha}^{-1}$, respectively).

Author Contributions: Conceptualization, C.D., F.P.; methodology, C.D., F.P.; software, F.P.; formal analysis, F.P., C.D., D.G.; investigation, F.P., C.D., K.B.; resources, K.B., D.G., C.D.; writing-original draft preparation, F.P.; writing-review and editing, C.D., D.G., K.B.; visualization, F.P.; supervision, C.D., D.G.; project administration, C.D., K.B.; funding acquisition, C.D., L.G.

Funding: This research was funded by FSOV [grant number FSOV-2012-E] (French fund for plant breeding).

Acknowledgments: We thank Stéphane Jezequel, Xavier Le Bris and Guillaume Meloux for their helpful comments on early drafts of this manuscript. We thank ARVALIS-Institut du végétal technical team located in Gréoux-les-Bains. Special thanks are also expressed to Arnaud Chapelet and Hanah Kuttler for their excellent assistance in the fieldwork. We thank three anonymous reviewers who helped to increase the clarity of the paper by their comments.

Conflicts of Interest: The authors declare no conflict of interest.

\section{References}

1. Alexandratos, N.; Bruinsma, J. World Agriculture towards 2030/2050: The 2012 Revision; ESA Working Paper No. 12-03; FAO: Rome, Italy, 2012.

2. Tilman, D.; Balzer, C.; Hill, J.; Befort, B.L. Global food demand and the sustainable intensification of agriculture. Proc. Natl. Acad. Sci. USA 2011, 108, 20260-20264. [CrossRef] [PubMed]

3. Reynolds, M.P.; Pfeiffer, W.H.; Royo, C. Applying physiological strategies to improve yield potential. Durum Wheat Improv. Mediterr. Reg. New Chall. Options Mediterranèennes 2000, 40, 95-103.

4. Brisson, N.; Gate, P.; Gouache, D.; Charmet, G.; Oury, F.X.; Huard, F. Why are wheat yields stagnating in Europe? A comprehensive data analysis for France. Field Crops Res. 2010, 119, 201-212. [CrossRef]

5. Iglesias, A.; Garrote, L.; Quiroga, S.; Moneo, M. A regional comparison of the effects of climate change on agricultural crops in Europe. Clim. Change 2012, 112, 29-46. [CrossRef]

6. Subira, J.; Ammar, K.; Álvaro, F.; Del Moral, L.F.G.; Dreisigacker, S.; Royo, C. Changes in durum wheat root and aerial biomass caused by the introduction of the Rht-B1b dwarfing allele and their effects on yield formation. Plant Soil 2016, 403, 291-304. [CrossRef]

7. Herder, G.D.; van Isterdael, G.; Beeckman, T.; De Smet, I. The roots of a new green revolution. Trends Plant Sci. 2010, 15, 600-607. [CrossRef] [PubMed]

8. Waines, J.G.; Ehdaie, B. Domestication and crop physiology: Roots of green-revolution wheat. Ann. Bot. 2007, 100, 991-998. [CrossRef]

9. Monti, A.; Zatta, A. Root distribution and soil moisture retrieval in perennial and annual energy crops in Northern Italy. Agric. Ecosyst. Environ. 2009, 132, 252-259. [CrossRef]

10. Manschadi, A.M.; Hammer, G.L.; Christopher, J.T.; deVoil, P. Genotypic variation in seedling root architectural traits and implications for drought adaptation in wheat (Triticum aestivum L.). Plant Soil 2008, 303, 115-129. [CrossRef]

11. Mathieu, L.; Lobet, G.; Tocquin, P.; Périlleux, C. "Rhizoponics": A novel hydroponic rhizotron for root system analyses on mature Arabidopsis thaliana plants. Plant Methods 2015, 11, 3. [CrossRef]

12. Mooney, S.J.; Pridmore, T.P.; Helliwell, J.; Bennett, M.J. Developing X-ray computed tomography to non-invasively image 3-D root systems architecture in soil. Plant Soil 2012, 352, 1-22. [CrossRef]

13. Metzner, R.; Eggert, A.; van Dusschoten, D.; Pflugfelder, D.; Gerth, S.; Schurr, U.; Uhlmann, N.; Jahnke, S. Direct comparison of MRI and X-ray CT technologies for 3D imaging of root systems in soil: potential and challenges for root trait quantification. Plant Methods 2015, 11, 17. [CrossRef] [PubMed] 
14. Rellán-Álvarez, R.; Lobet, G.; Lindner, H.; Pradier, P.L.M.; Yee, M.C.; Sebastian, J.; Geng, Y.; Trontin, C.; LaRue, T.; Lavelle, A.S. Multidimensional mapping of root responses to soil environmental cues using a luminescence-based imaging system. bioRxiv 2015, 16931.

15. Eberbach, P.L.; Hoffmann, J.; Moroni, S.J.; Wade, L.J.; Weston, L.A. Rhizo-lysimetry: facilities for the simultaneous study of root behaviour and resource use by agricultural crop and pasture systems. Plant Methods 2013, 9, 3. [CrossRef] [PubMed]

16. Watt, M.; Moosavi, S.; Cunningham, S.C.; Kirkegaard, J.A.; Rebetzke, G.J.; Richards, R.A. A rapid, controlled-environment seedling root screen for wheat correlates well with rooting depths at vegetative, but not reproductive, stages at two field sites. Ann. Bot. 2013, 112, 447-455. [CrossRef] [PubMed]

17. Sharma, B.R.; Chaudhary, T.N. Wheat root growth, grain yield and water uptake as influenced by soil water regime and depth of nitrogen placement in a loamy sand soil. Agric. Water Manag. 1983, 6, 365-373. [CrossRef]

18. Rich, S.M.; Watt, M. Soil conditions and cereal root system architecture: review and considerations for linking Darwin and Weaver. J. Exp. Bot. 2013, 64, 1193-1208. [CrossRef]

19. Barraclough, P.B.; Weir, A.H.; Kulhmann, H. Factors Affecting the Growth and Distribution of Winter Wheat Roots Under Uk Field Conditions. In Developments in Agricultural and Managed Forest Ecology; McMichael, B.L., Persson, H., Eds.; Elsevier: Amsterdam, The Netherlands, 1991; pp. 410-417.

20. Kmoch, H.G.; Ramig, R.E.; Fox, R.L.; Koehler, F.E. Root development of winter wheat as influenced by soil moisture and nitrogen fertilization. Agron. J. 1957, 49, 20-26. [CrossRef]

21. Barraclough, P.B.; Kuhlmann, H.; Weir, A.H. The Effects of Prolonged Drought and Nitrogen Fertilizer on Root and Shoot Growth and Water Uptake by Winter Wheat. J. Agron. Crop Sci. 1989, 163, 352-360. [CrossRef]

22. Herrera, J.M.; Stamp, P.; Liedgens, M. Dynamics of root development of spring wheat genotypes varying in nitrogen use efficiency. In Wheat Production in Stressed Environments; Springer: Dordrecht, The Netherlands, 2007; pp. 197-201.

23. Trachsel, S.; Kaeppler, S.M.; Brown, K.M.; Lynch, J.P. Shovelomics: high throughput phenotyping of maize (Zea mays L.) root architecture in the field. Plant Soil 2011, 341, 75-87. [CrossRef]

24. Maeght, J.L.; Rewald, B.; Pierret, A. How to study deep roots-and why it matters. Front. Plant Sci. 2003, 4, 299. [CrossRef] [PubMed]

25. Polomski, J.; Kuhn, N.; Waisel, Y.; Eshel, A.; Kafkafi, U. Root research methods. In Plant Roots: Hidden Half; Waisel, Y., Eshel, A., Beeckman, T., Kafkafi, U., Eds.; Springer: Berlin/Heidelberg, Germany, 2002; pp. $295-321$.

26. Wang, M.B.; Zhang, Q. Issues in using the WinRHIZO system to determine physical characteristics of plant fine roots. Acta Ecol. Sin. 2009, 29, 136-138. [CrossRef]

27. Munoz-Romero, V.; Benítez-Vega, J.; López-Bellido, L.; López-Bellido, R.J. Monitoring wheat root development in a rainfed vertisol: Tillage effect. Eur. J. Agron. 2010, 33, 182-187. [CrossRef]

28. Zadoks, J.C.; Chang, T.T.; Konzak, C.F. A decimal code for the growth stages of cereals. Weed Res. 1974, 14, 415-421. [CrossRef]

29. Justes, E.; Mary, B.; Meynard, J.M.; Machet, J.M.; Thelier-Huche, L. Determination of a Critical Nitrogen Dilution Curve for Winter Wheat Crops. Ann. Bot. 1994, 74, 397-407. [CrossRef]

30. Lobet, G.; Pagès, L.; Draye, X. A Novel Image-Analysis Toolbox Enabling Quantitative Analysis of Root System Architecture. Plant Physiol. 2011, 157, 29-39. [CrossRef]

31. Zhang, Z.S.; Li, X.R.; Wang, T.; Wang, X.P.; Xue, Q.W.; Liu, L.C. Distribution and Seasonal Dynamics of Roots in a Revegetated Stand of Artemisia ordosica Kracsh in the Tengger Desert (North China). Arid Land Res. Manag. 2008, 22, 195-211. [CrossRef]

32. Atkinson, D. Spatial and temporal aspects of root distribution as indicated by the use of root observation laboratory. In Ecological Interactions in Soil Special Publication Number 4 of the British Ecological Society; Fitter, A.H., Atkinson, D., Read, D.J., Usher, M.B., Eds.; Blackwell Scientific Publications: Oxford, UK, 1985; pp. 43-65.

33. Løes, A.K.; Gahoonia, T.S. Genetic variation in specific root length in Scandinavian wheat and barley accessions. Euphytica 2004, 137, 243-249. [CrossRef]

34. Keating, B.; Carberry, P.; Hammer, G.; Probert, M.; Robertson, M.; Holzworth, D.; Huth, N.; Hargreaves, J.N.; Meinke, H.; Hochman, Z.; et al. An overview of APSIM, a model designed for farming systems simulation. Eur. J. Agron. 2003, 18, 267-288. [CrossRef] 
35. Gregory, P.J. A Periscope Method for Observing Root Growth and Distribution in Field Soil. J. Exp. Bot. 1979, 30, 205-214. [CrossRef]

36. MerrillE, S.D.; Doering, E.J.; Reichman, G.A. Application of a Minirhizotron with Flexible, Pressurized Walls to a Study of Corn Root Growth 1. In Minirhizotron Observation Tubes: Methods and Applications for Measuring Rhizosphere Dynamics; Taylor, H.M., Ed.; ASA, CSSA, SSSA: Madison, WI, USA, 1987; Volume 50, pp. 131-143.

37. Upchurch, D.R.; Ritchie, J.T. Root observations using a video recording system in mini-rhizotrons. Agron. J. 1983, 75, 1009-1015. [CrossRef]

38. Johnson, M.G.; Tingey, D.T.; Phillips, D.L.; Storm, M.J. Advancing fine root research with minirhizotrons. Environ. Exp. Bot. 2001, 45, 263-289. [CrossRef]

39. Chaudhuri, U.N.; Kirkham, M.B.; Kanemasu, E.T. Root growth of winter wheat under elevated carbon dioxide and drought. Crop Sci. 1990, 30, 853-857. [CrossRef]

40. Li, F.M.; Liu, X.L.; Li, S.Q. Effects of early soil water distribution on the dry matter partition between roots and shoots of winter wheat. Agric. Water Manag. 2001, 49, 163-171. [CrossRef]

41. Allard, V.; Martre, P.; Le Gouis, J. Genetic variability in biomass allocation to roots in wheat is mainly related to crop tillering dynamics and nitrogen status. Eur. J. Agron. 2013, 46, 68-76. [CrossRef]

42. Fernandes, R.; Leblanc, S.G. Parametric (modified least squares) and non-parametric (Theil-Sen) linear regressions for predicting biophysical parameters in the presence of measurement errors. Remote Sens. Environ. 2005, 95, 303-316. [CrossRef]

43. Nakhforoosh, A.; Grausgruber, H.; Kaul, H.P.; Bodner, G. Wheat root diversity and root functional characterization. Plant Soil 2014, 380, 211-229. [CrossRef]

44. Hendricks, J.J.; Hendrick, R.L.; Wilson, C.A.; Mitchell, R.J.; Pecot, S.D.; Guo, D. Assessing the patterns and controls of fine root dynamics: an empirical test and methodological review. J. Ecol. 2006, 94, 40-57. [CrossRef]

45. Lopes, M.S.; Reynolds, M.P. Partitioning of assimilates to deeper roots is associated with cooler canopies and increased yield under drought in wheat. Funct. Plant Biol. 2010, 37, 147-156. [CrossRef]

46. Pradhan, G.P.; Prasad, P.V.V.; Fritz, A.K.; Kirkham, M.B.; Gill, B.S. Effects of drought and high temperature stress on synthetic hexaploid wheat. Funct. Plant Biol. 2012, 39, 190. [CrossRef]

47. Christopher, J.T.; Manschadi, A.M.; Hammer, G.L.; Borrell, A.K. Developmental and physiological traits associated with high yield and stay-green phenotype in wheat. Aust. J. Agric. Res. 2008, 59, 354. [CrossRef]

48. Barraclough, P.B.; Leigh, R.A. The growth and activity of winter wheat roots in the field: the effect of sowing date and soil type on root growth of high-yielding crops. J. Agric. Sci. 1984, 103, 59-74. [CrossRef]

49. Passioura, J.B. Grain yield, harvest index, and water use of wheat. J. Aust. Inst. Agric. Sci. 1977, 43, 117-120. 